\title{
MỐI QUAN HỆ GIŨ̃A ĐÒN BẨY TÀI CHÍNH VÀ KHẢ NĂNG SINH LÒ̀I CỦA CÔNG TY Ẋ MĂNG TRÊN THỊ TRƯờnG CHÚNG KHOÁN VIỆT NAM
}

\author{
NGUYẼ̃N THI THÚY HẠNH \\ Đại học Đà Nã̃ng, Phân hiệu Kon Tum; \\ ntthanh296@gmail.com
}

Tóm tắt. Nghiên cứu đo lường mối quan hệ giữa đòn bẩy tài chính và khả năng sinh lời của công ty xi măng Việt Nam niêm yết trên thị trường chứng khoán Việt Nam. Dữ liệu được thu thập từ báo cáo tài chính hàng năm đã được kiểm toán của 22 công ty xi măng trong giai đoạn từ năm 2009 đến năm 2016. Sử dụng mô hình hồi quy dữ liệu bảng, kết quả cho thấy đòn bầy tài chính và khả năng sinh lời có mối quan hệ với nhau. Hơn nữa, đòn bẩy tài chính tác động tiêu cực đến khả năng sinh lời của công ty xi măng Việt Nam. Kết quả có ý nghĩa ở mức $1 \%$. Đòn bẩy tài chính càng lớn thì lợi nhuận công ty sẽ càng giảm. Thêm vào đó, tác động của đòn bẩy tài chính đến thu nhập trên tổng tài sản và thu nhập trên vốn chủ sở hữu đều tương tự nhau, không có sự chênh lệch đáng kể về mức độ tác động.

Từ khóa. đòn bẩy tài chính, khả năng sinh lời, lợi nhuận, xi măng, tổng nợ

\section{A STUDY OF THE RELATIONSHIP BETWEEN FINANCIAL LEVERAGE AND CEMENT FIRM'S PROFITABILITY IN VIETNAM STOCK EXCHANGE}

\begin{abstract}
The study measured the relationship between financial leverage and profitability of cement listed companies in Vietnam stock market. Data were collected from the audited annual financial statements of 22 cement firms from 2009 to 2016. Using panel data regression, the results indicated the financial leverage and profitability of firm have relationship. Furthermore, the financial leverage negatively impacts on cement firms' profitability in Vietnam. The result is significant at the $1 \%$ level. The higher financial leverage is, the more profit decline. Besides, the impact of financial leverage on return on assets and return on equity were similar, with no significant difference in the level of impact.
\end{abstract}

Keywords. financial leverage, profitability, net income, cement, total debt

\section{GIÓ́I THIÊU}

Trong lĩnh vực tài chính, thuật ngữ “ đòn bẩy” được sử dụng khá phổ biến. Doanh nghiệp thường hay sử dụng 2 loại đòn bẩy: đòn bẩy hoạt động và đòn bẩy tài chính. Đòn bẩy hoạt động hay còn gọi là đòn cân định phí, phản ánh độ lớn của chi phí cố định ở doanh nghiệp, được biểu hiện bằng tỷ lệ của chi phí cố định so với tổng chi phí hoặc so với doanh thu. Đòn bẩy tài chính phản ánh mức sử dụng các nguồn tài trợ có chi phí tài chính cố định. Để mở rộng sản xuất kinh doanh, vay vốn ngân hàng là nhu cầu tất yếu đối với bất kỳ doanh nghiệp nào. Mức độ sử dụng nợ vay để tài trợ cho tài sản của doanh nghiệp được đo lường bằng đòn bẩy tài chính. Khi đó, sử dụng nợ vay càng nhiều sẽ làm tăng đòn bẩy trong công ty. Nếu công ty sử dụng nợ vay thì công ty phải trả lãi cho việc sử dụng nguồn vốn vay này. Kết quả là công ty phải chi trả nhiều hơn cho các chi phí tài chính cố định như lãi vay. Các chi phí này sẽ làm giảm lợi nhuận đạt được từ việc sử dụng đòn bẩy. Cuối cùng, việc lạm dụng đòn bẩy sẽ làm cho chính giá trị thị trường cổ phiếu của doanh nghiệp sụt giảm, hay đòn bẩy đã bị phản tác dụng, không những không làm gia tăng khả năng sinh lời của doanh nghiệp mà còn đẩy doanh nghiệp đứng trước nhiều tình thế khó khăn hơn. Khi nền kinh tế phát triển ổn định hay tăng trưởng thì đòn bẩy sẽ khuyếch đại lợi nhuận theo cấp số nhân. Tuy nhiên, trong giai đoạn khủng hoảng kinh tế, đòn bẩy sẽ dẫn đến thiệt hại theo cấp số nhân. Sử dụng nợ sẽ luôn đem đến mức độ rủi ro cao bởi vì thu nhập phải trả một phần cho nợ. Đòn bẩy tài chính được nghiên cứu trong bài là chỉ mức độ vay nợ của công ty.

Thời gian qua, có rất nhiều nghiên cứu về cấu trúc vốn, tập trung vào các nhân tố tác động đến cấu trúc vốn cũng như cấu trúc vốn tác động đến khả năng sinh lời của doanh nghiệp. Nghiên cứu về tác động của đòn bẩy tài chính đến lợi nhuận của doanh nghiệp được các nhà khoa học thế giới nghiên cứu từ rất 
lâu như Yoon \& Jang (2005); Akinlo \& Asaolu (2012); Fengju et al (2013) và Shamaileh \& Khanfar (2014). Theo Champion (1999) đòn bẩy là cách để cải thiện hiệu quả hoạt động của công ty. Abor (2007) tìm thấy mối quan hệ tích cực giữa nợ ngắn hạn và thu nhập trên tài sản (ROA) ở Nam Phi. Chinaemerem \& Anthony (2012) nghiên cứu tác động của cơ cấu vốn đến hiệu suất tài chính của công ty Nigera, sử dụng phương pháp Pooled OLS đã cho thấy cấu trúc vốn và cơ cấu tài sản tác động tiêu cực đến hiệu quả hoạt động. Trần Thị Kim Oanh (2017) phân tích số liệu 81 doanh nghiệp niêm yết trên sàn chứng khoán Việt Nam trong giai đoạn 2009-2015 với kỷ thuật xử lý dữ liệu bảng và hồi quy phân vị. Kết quả đã cho thấy hiệu quả hoạt động chịu sự tác động của cấu trúc vốn. Nawaz Ahmad et al (2015) đã chứng minh sự tác động đáng kể về mặt thống kê của biến độc lập là đòn bẩy tài chính đến lợi nhuận của 18 công ty xi măng được niêm yết trên thị trường chứng khoán Pakistan. Tuy nhiên, chưa có nhiều nghiên cứu về ảnh hưởng của đòn bẩy tài chính đến lợi nhuận công ty xi măng Việt Nam trong giai đoạn hiện nay. Chính vì thế, nghiên cứu tác động của đòn bẩy tài chính đối với lợi nhuận của công ty xi măng Việt Nam là rất cần thiết.

Nghiên cứu lựa chọn công ty xi măng niêm yết ở hai sàn chứng khoán HOSE và HNX. Dù ở bất kỳ một quốc gia nào, xi măng luôn là loại vật liệu xây dựng cơ bản và thông dụng nhất được sử dụng rộng rãi trong xây dựng cơ sở hạ tầng và phát triển kinh tế. Không những thế, ngành công nghiệp Xi măng là một ngành cần đầu tư khá lớn, vì vậy đòi hỏi đầu tư vào lĩnh vực xi măng nếu không là công ty chủ đạo của quốc gia, thì cũng phải là những tập đoàn lớn. Tuy nhiên, trong những năm gần đây, ngành xi măng đang trong giai đoạn rất khó khăn, lượng cung vượt quá lượng cầu, dẫn đến mức độ cạnh tranh trong ngành này khá khốc liệt. Trong giai đoạn 2009-2012, hệ số nợ phải trả trên tổng tài sản của doanh nghiệp xi măng niêm yết trên thị trường chứng khoán Việt Nam có xu hướng tăng từ $68 \%$ năm 2009 đến $70 \%$ năm 2012. Trong khi đó, hệ số vốn chủ sở hữu trên tổng tài sản có xu hướng giảm từ $32 \%$ năm 2009 xuống $30 \%$ năm 2012. Như vậy, cấu trúc nguồn vốn của doanh nghiệp xi măng niêm yết đang có sự biến động theo hướng tăng dần hệ số nợ và giảm dần hệ số vốn chủ sở hữu. Trong giai đoạn 2009-2013, cấu trúc tài chính theo quan hệ sở hữu xoanh quanh cấu trúc $60 \%$ nợ phải trả và $40 \%$ vốn chủ sở hữu. Từ 2014 đến nay, vốn chủ sở hữu tăng lên đạt $50 \%$ và nợ phải trả chiếm $50 \%$. Điều đó cho thấy việc gia tăng nguồn vốn bên trong giúp doanh nghiệp xi măng từng bước chủ động đáp ứng nhu cầu vốn cho các dự án đầu tư, tiết kiệm chi phí sử dụng vốn và tránh áp lực phải thanh toán nợ đúng kỳ hạn khi hoạt động tiêu thụ sản phẩm gặp nhiều khó khăn. Đồng thời, tăng cường đầu tư tài sản cố định, chi phí xây dựng cơ bản dở dang và tài trợ cho tài sản lưu động trong quá trình hoạt động kinh doanh. Bên cạnh đó, trong giai đoạn 2009 đến 2016, qui mô vốn và tài sản của doanh nghiệp xi măng không ngừng tăng lên, chứng tỏ doanh nghiệp xi măng ngày càng mở rộng hoạt động sản xuất kinh doanh. Để đáp ứng nhu cầu tăng trưởng, các doanh nghiệp xi măng niêm yết sử dụng nguồn vốn vay để tài trợ cho nhu cầu vốn kinh doanh là chủ yếu, cho thấy tính tự chủ, độc lập về mặt tài chính thấp. Trong cấu trúc vốn vay, chủ yếu là các khoản nợ ngắn hạn và có chi phí đã làm hạn chế khả năng thanh toán, khả năng đầu tư dài hạn. Thêm vào đó, thị trường bất động sản lại đóng băng, nhiều dự án phải dừng hoặc giãn tiển độ, nên nhu cầu tiêu thụ xi măng càng sụt giảm. Các doanh nghiệp muốn tồn tại và phát triển hay vượt qua các đối thủ cạnh tranh, thì cần phải phát huy tối đa sức mạnh và năng lực tài chính của chính doanh nghiệp. Việc xây dựng được cấu trúc vốn hợp lý cũng là cách để doanh nghiệp tối đa hóa sức mạnh tài chính. Chính vì thế, nghiên cứu sẽ đi phân tích rõ tác động của đòn bẩy tài chính đến khả năng sinh lời của công ty xi măng ở Việt Nam giai đoạn 2009 đến 2016.

\section{CÁC TÀI LIỆU NGHIÊN CÚU LIÊN QUAN}

Nhiều nghiên cứu đi trước đã chỉ ra rằng "Khả năng sinh lời" chịu ảnh hưởng bởi rất nhiều yếu tố khác nhau và đòn bẩy tài chính đã được chứng minh là có ảnh hưởng nhất định đến khả năng sinh lời. Đòn bẩy tài chính là khái niệm dùng để chỉ sự kết hợp giữa nợ phải trả và vốn chủ sở hữu trong việc điều hành chính sách tài chính của doanh nghiệp. Đòn bầy tài chính sẽ rất lớn trong các doanh nghiệp có tỷ trọng nợ phải trả cao hơn tỷ trọng của vốn chủ sở hữu. Ngược lại, đòn bẩy tài chính sẽ thấp khi tỷ trọng nợ phải trả nhỏ hơn tỷ trọng của vốn chủ sở hữu. Do đó, đòn bẩy thường được đo lường bằng tổng nợ phải trả chia cho tổng tài sản AhGhusinh, (2015); Vătavua (2015); Trần Mạnh Dũng và Nguyễn Huy Cường (2017). Khả năng sinh lời được đo lường bằng thu nhập trên vốn chủ sở hữu (ROE) và thu nhập 
trên tổng tài sản (ROA) như AhGhusin (2015); Trinh \& Phương (2015) và Trần Mạnh Dũng và Nguyễn Huy Cường (2017).

Mục tiêu cuối cùng của nhà quản trị là tối đa hóa lợi nhuận. Lợi nhuận là một chỉ tiêu tài chính tổng hợp phản ảnh hiệu quả của toàn bộ quá trình đầu tư, sản xuất, tiêu thụ và những giải pháp kỹ thuật, quản lý kinh tế tại doanh nghiệp. Để nhận thức đúng đắn về lợi nhuận thì không phải chỉ quan tâm đến tổng mức lợi nhuận mà cần phải đặt lợi nhuận trong mối quan hệ với vốn, tài sản, nguồn lực kinh tế tài chính mà doanh nghiệp đã sử dụng để tạo ra lợi nhuận trong từng phạm vi, trách nhiệm cụ thể. Do đó, khả năng sinh lợi thông thường được đo lường bằng tỷ suất lợi nhuận trên tổng tài sản (ROA) và tỷ suất lợi nhuận trên vốn chủ sở hữu (ROE) và các chỉ tiêu khác như EPS. Chính vì thế, nghiên cứu nhân tố tác động đến lợi nhuận của doanh nghiệp có vai trò rất quan trọng. Các nghiên cứu đi trước đã chỉ ra một số các yếu tố tác động đến lợi nhuận như đòn bẩy tài chính, qui mô doanh nghiệp, cơ cấu tài chính, tốc độ tăng trưởng... Đòn bẩy tài chính ám chỉ việc sử dụng chi phí tài chính cố định để gia tăng khả năng sinnh lợi của doanh nghiệp. Do đó, việc nghiên cứu tác động của đòn bẩy tài chính tới lợi nhuận của doanh nghiệp sẽ giúp doanh nghiệp đưa ra các biện pháp phù hợp. Các nhà quản trị tài chính của doanh nghiệp thường dựa vào các lý thuyết về cấu trúc vốn để đưa ra quyết định tài chính phù hợp. Lý thuyết của Modigliani và Miller (1958) là lý thuyết đầu tiên nghiên cứu về cấu trúc vốn của doanh nghiệp và đây cũng là nền tảng cơ sở để các lý thuyết sau này ra đời. Lý thuyết này giả định rằng, thị trường vốn là cạnh tranh hoàn hảo, không có sự tồn tại của thuế, không có chi phí giao dịch cũng như không có chi phí phá sản. Năm 1963, lý thuyết này tiếp tục nghiên cứu trong môi trường có thuế và đưa ra kết luận chi phí sử dụng vốn bình quân (WACC) của công ty sử dụng nợ thấp hơn công ty không sử dụng nợ. Năm 1984, lý thuyết trật tự phân hạng của Myers và Majluf ra đời. Dựa vào lý thuyết này, nguồn tài chính được phân hạng trước hết ưu tiên các nguồn vốn nội tại bên trong doanh nghiệp, vay nợ thứ hai và ưu tiên cuối cùng là phát hành cổ phiếu. Hàm ý rằng các công ty lợi nhuận cao sử dụng vốn từ lợi nhuận giữ hại và hạn chế vay nợ.

Kết quả nghiên cứu trước đây đa phần đều chỉ ra mối quan hệ tiêu cực giữa đòn bẩy tài chính và khả năng sinh lời của doanh nghiệp. Biger et al (2007) đã chỉ ra đòn bẩy tài chính làm giảm lợi nhuận của công ty Việt Nam năm 2002-2003. Nawaz et al (2015) cũng chứng minh mối quan hệ ngược chiều giữa đòn bẩy tài chính và lợi nhuận của 18 công ty xi măng tại Pakistan. Trần Mạnh Dũng và Nguyễn Huy Cường (2017) thu thập dữ liệu từ báo cáo tài chính của các công ty cổ phần niêm yết trên sàn giao dịch chứng khoán thành phố Hồ Chí Minh từ năm 2006 đến 2014, kết quả cho thấy đòn bẩy tài chính và khả năng sinh lời có mối quan hệ ngược chiều. Đây là hệ quả của mối quan hệ giữa chủ sở hữu và người sử dụng vốn trong doanh nghiệp, dẫn đến việc doanh nghiệp lạm dụng các công cụ tài chính và do sự yếu kém trong khả năng thẩm định tín dụng của ngân hàng Việt Nam.

Hiện nay, Việt Nam là một trong những nước sản xuất xi măng nhiều nhất thế giới, đáp ứng đủ nhu cầu tiêu thụ nội địa và xuất khẩu ra nhiều nước trên thế giới như Bangladesh, Singapore, Malaysia, Philippines, Đài Loan, Hong Kong (Trung Quốc). Số lượng nhà máy sản xuất xi măng không ngừng tăng lên, các doanh nghiệp xi măng cũng đã và đang không ngừng nâng cao dây chuyền công nghệ. Chính vì thế, nhu cầu về vốn cho các dự án sản xuất xi măng rất lớn, phần lớn được tài trợ bởi vốn vay ở các ngân hàng trong và ngoài nước. Vậy đòn bẩy tài chính sẽ tác động thế nào đến lợi nhuận của các công ty xi măng trong giai đoạn 2009 đến nay?

\section{THU THẬP DŨ LIỆU VÀ PHƯƠNG PHÁP NGHIÊN CÚU}

Nghiên cứu được tiến hành theo phương pháp thu thập dữ liệu thứ cấp từ các báo cáo tài chính hàng năm đã được kiểm toán của 22 công ty niêm yết trên sàn HOSE và HNX trong giai đoạn từ 2009 đến 2016.

Để nghiên cứu tác động của đòn bẩy tài chính đến khả năng sinh lời của công ty xi măng, nghiên cứu chạy mô hình hồi quy dưới đây

Trong đó:

$$
\mathbf{P}_{i, t}=\boldsymbol{\beta}_{0}+\beta_{1} * \mathbf{F L}_{i, t}+\mathbf{e}_{i, t}
$$

$\mathrm{P}$ đại diện cho khả năng sinh lời, được đánh giá bằng tỷ suất sinh lời trên tổng tài sản $(\mathrm{ROA})$ và tỷ suất sinh lời trên vốn chủ sở hữu (ROE) với:

$$
R O A_{i t}=\frac{\text { Lợi nhuận sau thuế }}{i t}
$$




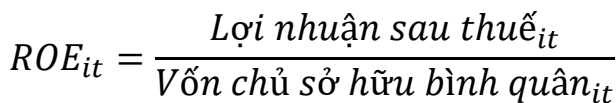

$$
\begin{aligned}
& F L_{i t}=\frac{\text { tổng nợit }}{\text { tổng tài sản bình quân } n_{i t}} \\
& \text { i: công ty thứ } \mathrm{i} \\
& \text { t: năm thứ } \mathrm{t}(\mathrm{t}=2009,2010 \ldots, 2016)
\end{aligned}
$$

Nghiên cứu chạy mô hình dữ liệu bảng để xem xét tác động của đòn bẩy tài chính đến khả năng sinh lời của công ty xi măng trên thị trường chứng khoán Việt Nam.

\section{KẾT QUẢ VÀ THẢO LUẬN}

\subsection{Thống kê mô tả các biến}

Bảng 1 trình bày giá trị nhỏ nhất, giá trị lớn nhất, giá trị trung bình và độ lệch chuẩn của hai biến đòn bẩy và lợi nhuận. Đòn bẩy tài chính có giá trị nhỏ nhất là 0,002 ; giá trị lớn nhất là 0,892 ; giá trị trung bình là 0,54 và độ lệch chuẩn 0,212 . Trong khi đó, ROA có giá trị nhỏ nhất là $-0,208$; giá trị lớn nhất là 0,199 ; giá trị trung bình là 0,039 và độ lệch chuẩn là 0,056 . ROE có giá trị nhỏ nhất là $-0,95$; giá trị lớn nhất là 0,482 ; giá trị trung bình là 0,077 và độ lệch chuẩn là 0,144 .

Bảng 1: Thống kê mô tả

\begin{tabular}{|l|l|l|l|l|}
\hline STT & Nội dung & ROA & ROE & FL \\
\hline 01 & Giá trị trung bình & 0,039 & 0,077 & 0,540 \\
\hline 02 & Độ lệch chuẩn & 0,056 & 0,144 & 0,212 \\
\hline 03 & Giá trị lớn nhất & 0,199 & 0,482 & 0,892 \\
\hline 04 & Giá trị nhỏ nhất & $-0,208$ & $-0,95$ & 0,002 \\
\hline
\end{tabular}

\subsection{Tác động của đòn bẩy tài chính đến lọi nhuận}

Bảng 2 trình bày hệ số hồi quy, $\mathrm{R} 2$ và giá trị $\mathrm{F}$ của mô hình hồi quy. Nghiên cứu chạy hồi quy dữ liệu bảng với tác động cố định và tác động ngẫu nhiên. Kết quả là hệ số hồi quy FL đều có giá trị âm, tức đòn bẩy tài chính sẽ tác động tiêu cực đến khả năng sinh lời của công ty xi măng. Cụ thể, đối với tác động cố định, FL có tác động ngược chiều đến $R O A$ và $R O E$ với giá trị tương ứng là $-0,1102$ và $-0,1384$. Đối với tác động ngẫu nhiên FL cũng có tác động ngược chiều đến $R O A$ và $R O E$ với giá trị tương ứng là 0,0927 và $-0,1075$. Qua đây ta thấy FL có tác động tới đến ROE và ROA có khác nhau nhưng không đáng kể. Nhìn chung, đòn bẩy tài chính tác động ngược chiều đều khả năng sinh lời.

Bảng 2: Hệ số hồi quy

\begin{tabular}{|l|l|l|l|l|}
\hline \multirow{2}{*}{} & \multicolumn{2}{|l|}{ Hệ số hồi quy với tác động cố định } & \multicolumn{2}{l}{ Hệ số hồi quy với tác động ngẫu nhiên } \\
\hline & ROA & ROE & ROA & ROE \\
\hline Hằng số & 0,0981 & 0,1513 & 0,0886 & 0,1346 \\
\hline FL & $-0,1102 * * *$ & $-0,1384 *$ & $-0,0927 * * *$ & $-0,1075^{*}$ \\
\hline R2 & 0,389 & 0,3655 & 0,0826 & 0,0166 \\
\hline F & 4,4279 & 4,0057 & 15,6721 & 2,9352 \\
\hline$* * * / * * * *$ thể hiện mức ý nghĩa tương ứng tại $1 \%, 5 \%$ và $10 \%$ & & \\
\hline
\end{tabular}


Bảng 3: Kiểm định Correlated Random Effects - Hausman Test

\begin{tabular}{|c|c|c|c|}
\hline \multicolumn{4}{|l|}{ Equation: Untitled } \\
\hline \multicolumn{4}{|c|}{ Test cross-section random effects } \\
\hline Test Summary & Chi-Sq. Statistic & Chi-Sq. d.f. & Prob. \\
\hline Cross-section random & 0.498035 & 1 & 0.4804 \\
\hline
\end{tabular}

Kết quả kiểm định ở bảng 3 cho thấy prob=0,4804, chứng tỏ việc chạy hồi quy dữ liệu bảng với tác động ngẫu nghiên là phù hợp. Do đó, nghiên cứu sẽ sử dụng kết quả ở bảng 2 , tác động cố định để phân tích. Hệ số beta của đòn bẩy tài chính (đối với biến ROE) là $-0,1075$, đối với ROA là $-0,0927$. Điều này chứng minh đòn bẩy tài chính có tác động đến lợi nhuận. Bên cạnh đó đòn bẩy tài chính tác động ngược chiều đến lợi nhuân của công ty xi măng. Điều này có thể được giải thích như sau: Giả thiết rằng quyết định đầu tư không đổi và như thế EBIT không đổi, các thay đổi của ROA và ROE là do quyết định tài trợ. Báo cáo tài chính của công ty xi măng cho thấy tồng nợ chiếm hơn $50 \%$ đến $70 \%$ nguồn vốn. Do đó, khi nợ vay tăng lên, lợi nhuận của công ty sẽ giảm do EBIT không đổi và chi phí lãi vay tăng lên. Mức giảm này nhiều hơn mức giảm của vốn chủ sở hữu nên ROE sẽ giảm. Đồng thời, nợ vay tăng lên khiến tổng tài sản sẽ tăng và dẫn đến ROA sẽ giảm. Kết quả nghiên cứu cho thấy, đòn bẩy tài chính tăng 1 đơn vị thì tỷ suất sinh lợi trên vốn chủ sở hữu sẽ giảm 0,1075 đơn vị và tỷ suất sinh lợi trên tài sản sẽ giảm 0,0927 đơn vị. Mức giảm của ROE tuy lớn hơn ROA nhưng không đáng kể. Kết quả nghiên cứu phù hợp với kết quả các nghiên cứu đi trước.

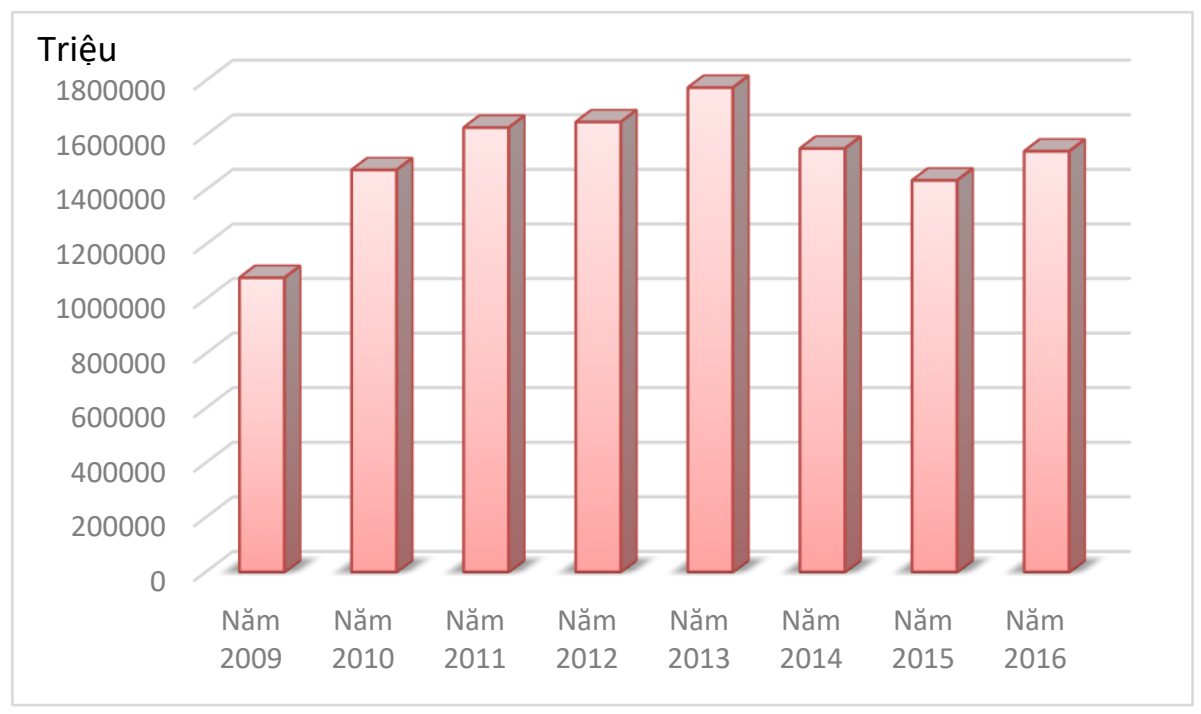

Hình 1: Tổng nợ trung bình của tất cả công ty từng năm từ 2009-2016

Dựa vào hình 1, ta thấy tổng nợ bình quân tăng dần từ năm 2009 đên 2013 và có sự sụt giảm nhẹ vào giai đoạn từ 2014 đến 2015 . Từ số liệu thu thập từ các công ty xi măng, đa phần các công ty đều mở rộng hoạt động kinh doanh bằng cách vay nợ dẫn đến tổng nợ từ năm 2009 đến năm 2013 của các công ty xi măng đều tăng đáng kể, giai đoạn từ 2014 đến 2015 có sự sụt giảm do ảnh hưởng của thị trường vốn trong nước nhưng qua năm 2016 đã tăng trở lại, trong khi đó chi phí lãi vay phải trả cao, làm giảm lợi nhuận sau thuế của công ty. 


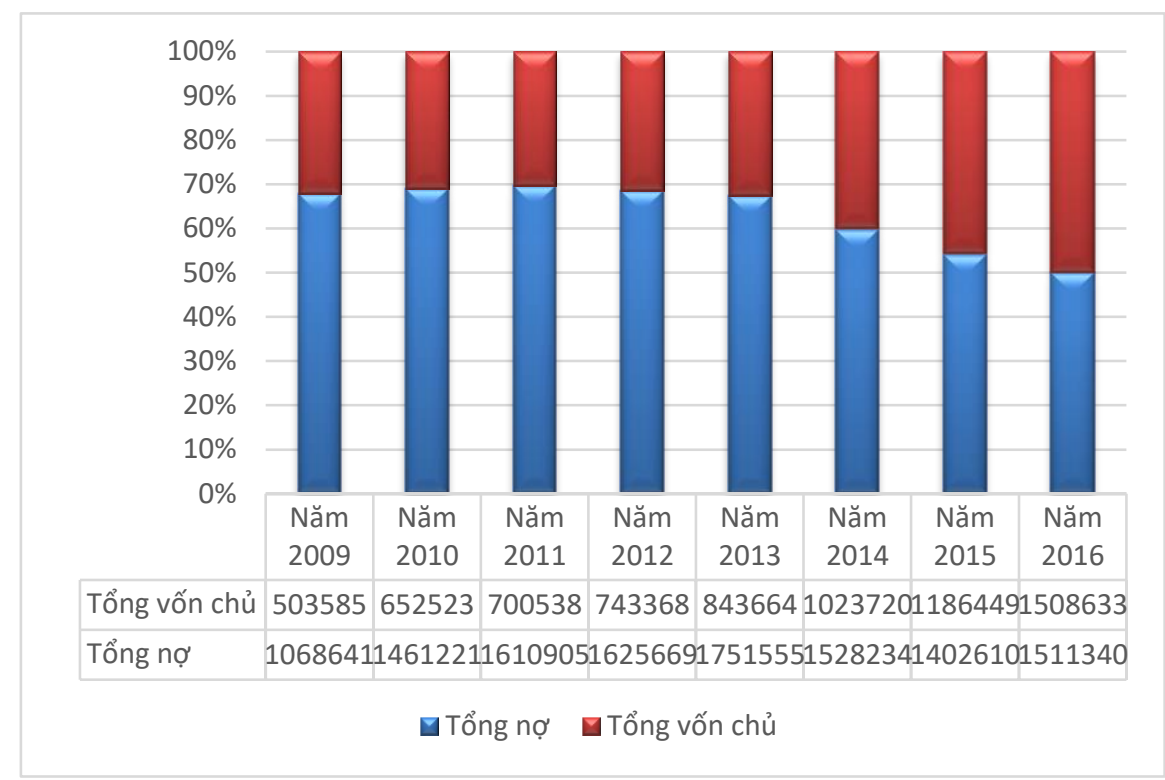

Hình 2: Cơ cấu vốn bình quân của các công ty xi măng Việt Nam từ 2009-2016

Dựa vào hình 2 cho thấy cấu trúc vốn của công ty xi măng giai đoạn 2009-2016. Từ năm 2009 đến 2013, tổng nợ chiếm tỷ trọng rất cao, chiếm 70\% nguồn vốn và từ năm 2014 đến nay tỷ trọng nợ đã giảm nhưng còn chiếm $50 \%$. Điều này có thể lý giải do trước năm 2013, hoạt động vay nợ của các công ty xi măng được nới lỏng do được sự bảo lãnh của chính phủ. Cụ thể vào tháng 3-2012, Bộ Xây dựng cho biết có tới 11 dự án xi măng được Chính phủ bảo lãnh vay nước ngoài với tổng số tiền lên tới gần 300 triệu USD và 445 triệu euro (tương đương 17.000 tỉ đồng). Các công ty xi măng đã tận dụng khai thác nguồn vốn vay từ bên ngoài, dẫn đến năm 2013 thị trường bất động sản đóng băng, các công ty xi măng không bán được sản phẩm nên không thể trả được nợ vay.

Chính vì thế, hoạt động vay nợ của các công ty này bị thắt chặt lại. So với những năm trước 2012 thì tổng nợ phải trả của các công ty đã giảm những đã có xu hướng tăng trở lại, tuy nhiên vẫn nhỏ hơn so với trước, chiếm khoảng hơn $50 \%$ tổng nguồn vốn của công ty. Hiện nay thị trường bất động sản đã có dấu hội khôi phục với hàng loạt dự án đầu tư xây dựng khởi công, nhu cầu tiêu thụ xi măng nội địa đã có dấu hiệu tăng trưởng ổn định và nhận được những tín hiệu tích cực từ thị trường xuất khẩu.

\subsection{Các kiểm định khác}

Kết quả kiểm định ở Bảng 4 cho thấy xác suất (chuẩn $\mathrm{F}$ ) < 0,05 và $\mathrm{R} 2$ điều chỉnh là 0,13 đã khẳng định việc dùng mô hình ước lượng dữ liệu bảng là phù hợp.

Bảng 4: Breusch-Godfrey Serial Correlation LM Test

\begin{tabular}{lllr}
\hline \hline F-statistic & 14,67675 & Prob, F(2,172) & 0,0000 \\
Obs*R-squared & 25,65744 & Prob, Chi-Square(2) & 0,0000 \\
\hline \hline
\end{tabular}

Bảng 5: Heteroskedasticity Test: Breusch-Pagan-Godfrey

\begin{tabular}{lllr}
\hline \hline F-statistic & 1,013495 & Prob, F(1,174) & 0,3155 \\
Obs*R-squared & 1,019208 & Prob, Chi-Square(1) & 0,3127 \\
Scaled explained SS & 1,162754 & Prob, Chi-Square(1) & 0,2809 \\
\hline \hline
\end{tabular}


Bảng 6: Kiểm định phương sai sai số thay đổi

\begin{tabular}{lrrr}
\hline \hline & Heteroskedasticity Test: White & \\
\hline \hline F-statistic & 1,197536 & Prob, F(2,173) & 0,3044 \\
Obs*R-squared & 2,403333 & Prob, Chi-Square(2) & 0,3007 \\
Scaled explained SS & 2,741821 & Prob, Chi-Square(2) & 0,2539 \\
\hline \hline
\end{tabular}

Bảng 5 và bảng 6 trình bày kết quả kiểm định phương sai sai số thay đổi và tự tương quan. Kết quả nghiên cứu đều lớn hơn $10 \%$, cho thây mô hình không có hiện tượng phương sai sai số thay đổi và tương quan chuỗi.

\section{KếT LUẬN}

Nghiên cứu đo lường ảnh hưởng của đòn bẩy tài chính đến khả năng sinh lời của công ty xi măng Việt Nam trên thị trường chứng khoán Việt Nam. Dữ liệu được thu thập từ báo cáo tài chính hàng năm đã được kiểm toán của 22 công ty xi măng từ năm 2009 đến năm 2016. Sử dụng mô hình hồi quy dữ liệu bảng với tác động cố định là công ty, kết quả cho thấy đòn bẩy tài chính tác động tiêu cực đến khả năng sinh lời của công ty xi măng Việt Nam. Kết quả có ý nghĩa ở mức $1 \%$. Điều này cho thấy nếu công ty sử dụng đòn bẩy tài chính càng lớn bằng việc vay nợ càng nhiều thì sẽ làm giảm lợi nhuận. Bên cạnh đó, tác động của đòn bẩy tài chính đến thu nhập trên tổng tài sản và thu nhập trên vốn chủ sở hữu đều tương tự nhau, không có sự chênh lệch đáng kể về mức độ tác động. Đây là dấu hiệu cảnh báo các nhà quản lý tài chính của các công ty xi măng Việt Nam đối với việc huy động vốn bằng cách vay nợ. Do đó, doanh nghiệp cần gia tăng vốn chủ sở hữu từ phần lợi nhuận giữ lại, thực hiện các giải pháp tăng doanh thu và giảm chi phí, hạ giá thành sản phẩm. Ngoài ra, doanh nghiệp cần đa dạng hình thức huy động vốn chủ sở hữu thông qua phát hành cổ phiếu thường và cổ phiếu ưu đãi. Trong thời gian tới, khi nền kinh tế tăng trưởng trở lại, nhu cầu tiêu thụ xi măng đang có dấu hiệu tăng, các doanh nghiệp xi măng có khả năng tài chính sẽ dễ dàng tiếp cận nguồn vốn vay trung và dài hạn từ ngân hàng thương mại. Từ đó, các doanh nghiệp có thể đầu tư, nâng cao năng lực sản xuất. Bên cạnh đó, ngoài nguồn vốn vay từ ngân hàng, doanh nghiệp nên xem xét các phương thức dài hạn khác như phát hành trái phiếu, cho thuê tài chính, cho thuê vận hành. Cuối cùng, kết quả nghiên cứu cho thấy mối quan hệ ngược chiều của đòn bẩy tài chính và lợi nhuận, do đó các nhà quản trị doanh nghiệp không nên vay nợ thêm nữa, cần ưu tiên tài trợ bằng nguồn vốn chủ sở hữu và đàm phán với chủ nợ để chuyển nợ thành vốn cổ phần, phát hành cổ phiếu.

Bên cạnh đó, việc nhà nước cần cân nhắc và rà xoát lại việc cấp vốn các dự án sản xuất xi măng, việc bảo lãnh của nhà nước đã tạo điều kiện cho các công ty xi măng được vay nợ. Cơ quan ban ngành nên tạo điều kiện thức đẩy sự liên kết của các dự án sản xuất xi măng, mở rộng qui mô, đổi mới công nghệ, tránh tình trạng sử dụng công nghệ mua lại đã cũ dẫn đến ô nhiễm môi trường, chi phí sản xuất cao và năng suất thấp. Do đó, sự điều tiết và quản lý nhà nước đối với các dự án xi măng là vô cùng quan trọng. Mặt khác, các doanh nghiệp xi măng cần có sự phối hợp, liên kết với nhau nhiều hơn nữa, giảm tình trạng sản xuất dư thừa, vượt quá nhu cầu xi măng. Hơn thế, các công ty xi măng qui mô còn nhỏ lẻ và phân tán, nên khó giảm chi phí sản xuất, do đó sự phối hợp của các công ty là vô cùng cần thiết, tránh tình trạng bị ép giá khi xuất khẩu. Đồng thời, các công ty cần phải giảm chi phí, đầu tư máy móc để có giá bán thấp đủ sức cạnh tranh trên thị trường quốc tế.

\section{TÀI LIỆU THAM KHẢO}

[1] Abor, J. (2005). The effect of capital structure on profitability: an empirical analysis of listed firms in Ghana. The journal of risk finance, 6(5), 438-445.

[2] ALghusin, N. A. S. (2015). Do Financial Leverage, Growth and Size Affect Profitability of Jordanian Industrial Firms Listed? International Journal of Academic Research in Business and Social Sciences, 5(4), 335-348. 
[3] Biger, N., Nguyen, N. V., \& Hoang, Q. X. (2007). Chapter 15-The determinants of capital structure: Evidence from Vietnam. Asia-Pacific Financial Markets: Integration, Innovation and Challenges (International Finance Review, Volume 8), Emerald Group Publishing Limited, 307-326.

[4] Champion, D. (1999), "Finance: the joy of leverage”, Harvard Business Review, Vol. 77 No. 4, pp. 19-22

[5] Chinaemerem, O. C., \& Anthony, O. (2012). Impact of capital structure on the financial performance of Nigerian firms. Oman Chapter of Arabian Journal of Business and Management Review, 1(12), 43-61.

[6] Dwi Kartikasari - Marisa Merianti. International Journal of Economics and Financial Issues, 2016, 6(2), 409413.

[7] Eunju Yoon and SooCheong Jang (2005). "The Effect of Financial Leverage on Profitability and Risk of Restaurant Firms". Journal of Hospitality Financial Management: Vol. 13: Iss. 1, Article 24.

[8] Gu, Z. (1993). Debt use and profitability: A reality check for the restaurant industry. Foodservice Research International, 7(3), 135-147.

[9] Metin Uyar (2014). A Research on Total Cost of Ownership and Firm Profitability. Research Journal of Finance and Accounting, ISSN 2222-1697 (Paper) ISSN 2222-2847 (Online), Vol.5, No.1, 2014.

[10] Modigliani, F. \& Miller, M.H (1958). The cost of capital, corporate finance and the theory of Investment, The American Economic Review, 48 (3),261-297.

[11] Modigliani, F. \& Miller, M.H (1963). Corporate Income Taxes and the cost of capital: A Correction, The American Economic Review, 53 (3),433-443.

[12] Myers, S.C.\& Majluf,N.S. (1984). Corporate financing and investment decisions when firms have information that investors do not have, Jounal of Financial Economic, 13, 187-221.

[13] Nawaz, A., Salman, A., \& Shamsi, A. F. (2015). Impact of Financial Leverage on Firms' Profitability: An Investigation from Cement Sector of Pakistan. Research Journal of Finance and Accounting, 6(7), 22221697.

[14] Nguyen, D. T., Diaz-Rainey, I., \& Gregoriou, A. (2012). Financial development and the determinants of capital structure in Vietnam. Available at SSRN 2014834.

[15] Nguyen, T. D. K., \& Ramachandran, N. (2006). Capital structure in small and medium-sized enterprises: the case of Vietnam. ASEAN Economic bulletin, 23(2), 192-211.

[16] Shamaileh, M. O., \& Khanfar, S. M. (2014). The effect of the financial leverage on the profitability in the tourism companies (analytical study-tourism sector-Jordan). Business and Economic Research, 4(2), 251.

[17] Sheel, A. (1994). Determinants of capital structure choice and empirics on leverage behavior: A comparative analysis of hotel and manufacturing firms. Journal of Hospitality \& Tourism Research, 17(3), 1-16.

[18] Trần Mạnh Dũng và Nguyễn Huy Cường (2017). Tác động của quản trị vốn lưu động đến khả năng sinh lời. Bằng chứng từ các công ty niêm yết trên sàn chứng khoán Hồ Chí Minh. Tạp chí Kinh tế \& Phát triển, 235, 71-78.

[19] Trần Thị Kim Oanh (2017). Cấu trúc vốn và hiệu quả hoạt động của doanh nghiệp Việt Nam: Tiếp cận bằng hồi quy phân vị. Tạp chí Kinh tế \& Phát triển, 235, 60-70.

[20] Vătavua S. (2015). The impact of capital structure on financial performance in Romania list companies. Procedia Economics and Finance, 32, 1314-1322.

[21] Xu Fengju - Rasool Yari Fard - Leila Ghassab Maher - Nader Akhteghan, European Online journal of Natural and Social Sciences 2013, vol.2, No. 3(s), pp.156-164. 